\title{
Comparing manual and remote sensing field discontinuity collection used in kinematic stability assessment of failed rock slopes
}

Luis Jordá Bordehore(1), Adrian Riquelme (2), Miguel Cano (2), Roberto Tomás (2)

(1) Instituto Geológico y Minero de España (Geological Survey of Spain), Rios Rosas 23, Madrid

Corresponding autor: 1.jorda@igme.es

(2) Civil Engineering Department, University of Alicante, Carretera San Vicente del Raspeig, s/n, 03690 San Vicente del Raspeig, Alicante, Spain.

ariquelme@ua.es,.es, miguel.cano@ua.es, roberto.tomas@ua

\section{Introduction}

Data collection for kinematic and structural analyses in hills or rock slopes still maintains, nowadays, an important manual component. The set of lithological, structural and characteristic observations of the rock mass, directed to engineering design, is referred to as geomechanics observation point or geomechanical station. The properties and orientation of discontinuities and rock matrix of a geomechanics observation point are obtained in situ, by normalized templates([1]; [2]). Subsequent laboratory/office work determines the resistant properties of the discontinuities, evaluates the geomechanical quality of the rock mass (e.g. using the RMR, Q, or GSI indices) and carries out a census of discontinuities, grouping into main sets. Field data are combined with laboratory results, in situ and geophysical tests, with the objective of elaborating a "geomechanical model" of the rock mass. Field characterization plays an important role in preliminary studies and, in many cases, is the only information available in the first stages of investigation and project development.

Traditionally, rock mass field data collection has been carried out by physically accessing the slope. However, remote acquisition techniques have provided a new perspective. The main two remote data collection techniques are Interferometric Synthetic Aperture Radar -InSAR-and Light Detection and Ranging -LiDAR [3], [4].InSAR enables high precision measurements of terrain surface movements, and is usually applied to monitor and detect landslides. LiDAR provides a 3D point cloud of the 
terrain surface. The comparison of point clouds acquired in different time frames also enables the monitoring and detection of landslides. Additionally, the use of 3D point clouds offers the possibility of working with geometrical surface information. Complementarily, digital photography has experienced significant advances with the development of photogrammetry techniques.

The Structure from Motion (SfM) technique must be highlighted, as it enables surface reconstruction from 3D point clouds of digital photographs. SfM is considered a high-resolution, low-cost automated photogrammetry method, and it is based on the same principles of stereoscopic photogrammetry (the 3D structure can be built from image superposition). SfM originated from the artificial vision area and from the development of automated algorithms for digital image correlation (DIC). SfM is different from conventional photogrammetry, as the scene geometry, camera positions and orientation are solved automatically without the need of establishing, a priori, a control point network with known 3D coordinates. Collinearity equations are solved from the high number of conjugated points (common image points) identified during the automatic correlation phase of a set of superimposed images acquired in an unstructured way [5], [6]. The equipment utilized in the application of this technique entails lower economic costs than with LiDAR instrumentation, and results are reasonably acceptable [7]. The limitation of SfM is mainly the dependence on the quality of the lens and the processing time, the procedure for capturing images and resource consumption by the machine. Generally, the higher the number, quality and resolution of the images, the higher the quality of the generated model. This, however, entails in a higher consumption of resources and higher computational time

3D point cloud treatment enables semi-automatic identification and extraction of information from plane discontinuity sets [8]. Such information is very important for the development of kinematic analyses of block-controlled instabilities. The SfM technique [9] has been attracting attention and becoming popular, as indicated by the increasing number of publications [9], [10]. These techniques permit the characterization of important geomechanical parameters such as orientation[11], [12], [13], [14], roughness[15] and persistence and spacing of discontinuities [16], [17], [18].

Of all geomechanical parameters that can be extracted from 3D point clouds, analysis of plane discontinuities has probably been the most approached subject to this date [14], [19], [20], [21], [22], [23], [13], [10], [24], [25], [26]. All proposed methods 
analyze the surface of the slope from 3D point clouds or from reconstruction via triangular elements (TIN, Triangular Irregular Network). In each surface point or element, the normal vector is estimated and a pole is determined; as a result, there is a population of poles available to analyze predominant surface orientations.

The overarching objective of this work is to compare the results obtained in the collection of discontinuity orientations using a low-cost remote technique (i.e. SfM) and manual collection (compass). To this end, orientations are gathered with a compass for all accessible discontinuities of a slope, and from all discontinuities that are well represented in the 3D point cloud obtained with SfM. Plane extraction and 3D model orientations are carried out in two different ways: (1) by adjusting the planes to the point sets that belong to the same discontinuity, with Cloud Compare software [27]; and (2) semi-automatically, with Discontinuity Set Extractor software, DSE[12]. The focus herein is only on the collection of discontinuity orientations, not on rock mass properties [28].

\section{Study case}

The studied slope is located at the construction site of a roadway, approximately $6 \mathrm{~m}$ high, excavated in slates of the Ordovician Period. It is located next to the El Atazar Dam, $70 \mathrm{~km}$ north of Madrid (Figure1). During a field campaign carried out in 2014 [28], discontinuity orientation data were obtained manually with a compass (Table 1), along with geomechanical data. Three main joint sets were determined: $\mathrm{S}_{0}$ (foliation), and two joints, $\mathrm{J}_{1}$ and $\mathrm{J}_{2}$. Additionally, kinematic analysis was carried out, which allowed for the identification of a planar failure in the slope (Figure 1). The planar failure of the slope is produced by foliation $\left(\mathrm{S}_{0}\right.$, highlighted in yellow in Figure 1$)$, which is easily recognized after visual inspection. Joint set $\mathrm{J}_{1}$, of difficult access, also plays a fundamental role in the kinematics of this landslide (highlighted in red, Figure 1). At the upper part of the slope, joint set $\mathrm{J}_{1}$ is better represented, delimiting the fallen block. Nevertheless, in this high zone, joint set $\mathrm{J}_{1}$ presents a challenging location for data acquisition with a compass.

\section{3- Methodology}

\subsection{Generalities}

In rock engineering, the orientation of any plane (i.e. joints, faults, strata or veins) is represented by dip angle and dip direction. The universally employed tool for 
measuring orientation regarding the magnetic north is the compass, which requires physical access of the operator to the location. Frequently it is not possible to collect orientation measurements manually with a compass, as the slope or part of it is inaccessible or unsafe. In these cases, if possible, secondary discontinuities or discontinuity sets are measured in other zones of the slope (more accessible, safer locations). Measurements of different types of discontinuities (e.g., foliation, bedding, joints) are subsequently analysed in laboratory settings, and grouped in clusters or groups of discontinuities with coherent orientation (also called sets [28]). This grouping can be carried out manually, through the application of methodologies such as Kalsbeek counting net [29], or automatically, through the identification of data clusters in polar or stereographic projections[30].

As an alternative to manual data collection, analysis can be carried out from orientation data derived from the analysis of 3D point clouds. The SfM technique can present errors in the model generated due to, among other factors, distortion of the lenses utilized to acquired digital images. Some authors propose that photographs are taken with a specific inclination regarding the interest surface [31] but other programs recommend taking photographs perpendicularly to the surface and correct the internal parameters of the camera through the introduction of control points with known coordinates [32].

\subsection{Photographs and manual measurement of orientations}

During the field campaign developed for this work, 58 manual orientation measurements were acquired with a compass on some plane surfaces - joints- of the slope. Also, 35 photographs were taken with an amateur digital Nikon Coolpix S2800 "low cost" camera, to generate a 3D point cloud with the SfM methodology. The Agisoft Photoscan Professional software was utilized for the extraction of discontinuity orientations (Figure 2 ). The aim of the $3 \mathrm{D}$ point cloud is to create a $3 \mathrm{D}$ reconstruction or digital image of the slope, allowing for the extraction or obtainment of more planar surfaces (joints) to improve the quality of the joint sets

\subsection{Obtainment of the 3D point cloud}

It is necessary to identify and define planar discontinuity sets from the generated $3 \mathrm{D}$ point cloud to characterize the rock mass of a roadway slope,. For such, the $3 \mathrm{D}$ point cloud must be appropriately scaled and oriented, and it is necessary that distortions are minimized. At least three points of the slope are required for scaling and orientation. 
Although this information enables the determination of the rigid transformation matrix to be applied, it is expected that the resulting model presents scaling, orientation and deformation deviations. This can be mostly avoided with the use of Bundle Adjustment, for which it is necessary to utilize Ground Control Points (GCP). Nevertheless, the results depend on the number and quality of the GCP employed.

The methodology herein applied is simple to implement in zones of difficult access, and enables the collection of GCP in remote locations, without the help of topography equipment. This could lead to some errors, up to $\pm 2^{\circ}$ for high quality compasses and $\pm 5^{\circ}$ for difficultly positioned devices or exposed outcrops, mine stopes, etc. This fact could not be ignored, and depends on the scope of the research or project (orientation of bolts, displacement monitoring, etc.). In this case, we propose a methodology that can be transferred to remote locations where conventional topographic equipment could not be easily transported, during prefeasibility stages of the project. In these stages, fast evaluation of the main stability mechanisms is more important than very accurate calculations with low field data. The studied slope serves as a test location to evaluate the possibilities of applying this methodology and the precision of the technique. The methodology consists of selecting at least three GCP for an accessible zone of the slope (Figure 3). Initially, a point is selected at an accessible, easily recognized location in the slope; this point is established as the origin of a relative reference system $(0,0,0)$. Then, coordinates of the other GCP are obtained, measuring distances and directions regarding the magnetic north, with the aid of a compass. All GCP are marked on the slope with coloured modelling clay, for easy identification in the field and in frames. In this way, the coordinates of three slope points are known, which will allow for the scaling and orientation of the point cloud generated, and therefore for the extraction of real discontinuity orientations. Crosses measuring 5-10 cm were utilized, and distances were measured with a rigid tape.

In the studied slope, the point marked as " 1 " was taken as the relative coordinate origin (0,0,0 shown in red in Figure3). The other points, "2" and " 3 " (marked in blue and white, respectively, in Figure3), were taken with reference to "1". From point 1, the dip angle and direction of the vector defined by points 1-2 and 1-3 was determined. Subsequently, with the measured distance between these points, coordinates of points " 2 " and " 3 " were determined, taking " 1 " as reference. 
3.3. Extraction of discontinuities and comparison of orientations: validation

From the 3D point cloud obtained, discontinuity sets were determined by two different procedures: a) selection of point groups from a discontinuity and fitting by least square method of a plane; and b) semi-automatically, using the open-source software: Discontinuity Set Extractor [12].

Three control planes were employed to evaluate the deviation between the compass field-measured orientations and those extracted from the 3D point cloud. These are planar discontinuity surfaces of the slope. Coloured clay is utilized to place arrows pointing towards the dip direction of the plane, for easy identification after photogrammetry restitution (Figure 4). These planes are measured manually with a compass at one point of the surface, and from the 3D point cloud of the slope by fitting to a plane with the Cloud Compare software [27]. Foliation plane $\mathrm{S}_{0}$, in the zone where the identification mark was situated, presented a small roughness-step, and exceptionally, two measurements were taken instead of one (Figure 4e).

Dispersion of the orientations measured by the different methods (remote and manual) was evaluated by Fisher's K constant, which is a measure of the scatter about the mean orientation of a discontinuity [33]. A high $\mathrm{K}$ value (e.g., 50) implies in a more concentrated discontinuity group than a lower value of K (e.g., 20), which represents a more disperse group.

\section{Results}

Reference plane $\mathrm{S}_{0}$, marked for remote analysis, is shown in Figure4 a and c. Joint $\mathrm{J}_{1}$ (marked in red in Figure4-b and e) corresponds to an overhanging mode joint that dips into the slope and acts as a tension crack for the planar sliding produced on $\mathrm{S}_{0}$.

Comparison of the orientation values of the planes determined with a compass and with the $3 \mathrm{D}$ point cloud resulted in high coincidence, with differences in the distances between poles obtained of $5^{\circ}$ and- $9^{\circ}$, in the case of undulating S0 -(Figure 4 and 5). This difference is reasonable and coherent with the common precisions accepted during characterization of slopes that present challenging access or complicated transit (e.g., jungle, mountain). Also, these errors are similar to those produced during manual collection of orientations with a compass (between 2 and $5^{\circ}$ ). 
Figure 6a shows the 58 poles obtained manually with a compass during the field campaigns of 2014 and 2015. The three main sets identified $\left(S_{0}, J_{1}\right.$ and $\left.J_{2}\right)$ are shown in Table 3 along with dip angles and directions, and $\mathrm{K}$ distributions. Figure $6 \mathrm{~b}$ shows the result of pole analysis carried out from the orientations obtained by manual plane adjustments on the 3D point cloud. Special attention was devoted to the upper part discontinuities, and therefore more values are shown for the $\mathrm{J}_{1}$ discontinuity set than for $\mathrm{J}_{2}$. It is worth noting that discontinuity $\mathrm{J} 1$ controls stability and delimitates the fallen block. Figures $6 \mathrm{c}$ and $6 \mathrm{~d}$ show the combination of poles obtained with compass and with the $3 \mathrm{D}$ point cloud. The measurement increment improves considerably the original stereogram obtained via compass, contributing with additional data for the upper part of the slope. Regarding data dispersion, Fisher's $\mathrm{K}$ is lower in the case of slate - foliation $\left(\mathrm{S}_{0}\right)$ and joint $J_{2}$, due to the higher number of employed samples. Nevertheless, $K$ is higher in joint $\mathrm{J}_{1}$ (i.e., lower measurement dispersion) as a higher number of values was employed (Table 2).

Once results were validated through comparison planes, slope discontinuities were extracted semi-automatically from the 3D point plane utilizing the DSE software [7], [10], [16], [12], (Figure7). The DSE software carries out pole census from an elevated number of measurements (370,900 orientation measurements) (Figures $7 \mathrm{a}$ and 7b). Figure 7c shows the photogrammetric restitution of the slope using the SfM technique and Figure $7 \mathrm{~d}$ shows the classified 3D point cloud, where each colour represents a different set of discontinuities: $\mathrm{S}_{0}$ (yellow), $\mathrm{J}_{2}$ (green) and $\mathrm{J}_{1}$ (red).

The stereogram shown in Figure 8 was built to compare stereograms of manual data (Figure 6) and automatic extraction (Figure 7), which was randomly reduced from 370,900 poles to 300 . The DSE software operates within the MATLAB environment but Dips software [30] failed when loading the massive amount of data. It can be observed how a zone with an abundance of poles can be established as one only plane set (foliation) $\mathrm{S}_{0}$, instead of two sets, $\mathrm{S}_{0}$ and $\mathrm{J}_{2}$. However, set $\mathrm{J}_{1}$ is very relevant at a geotechnical stability level, presents few planes (although important), and is clearly masked by the large amount of data of predominant sets $\mathrm{S}_{0}$ and in its case, $\mathrm{J}_{2}$ (Figures 7 and 8).

Kinematic analysis was carried out with combined data (Figures $6 \mathrm{c}$ and $6 \mathrm{~d}$, and Table 2), which is shown in the stereogram of Figure 9. The graphical scheme for the kinematic analysis was built using the poles of the slope and the poles of the joints with 
restricted daylight envelope to define stable /unstable situations [28]. The failure of the slope could have been produced not only in favour of $S_{0}$, with discontinuity $J_{1}$ acting as tension crack (or block top fracture - boundary), but discontinuity $\mathrm{J}_{2}$ (with similar orientation to $\mathrm{S}_{0}$, but higher dip) could have acted as a sliding plane. Generation of a combined cloud for $\mathrm{S}_{0}$ and $\mathrm{J}_{2}$, and further comparison of restricted daylight envelopes results in a series of poles (in red) belonging to an unstable zone. Poles in green would belong outside this zone, being therefore stable (Figure 9).

\section{Discussion}

No data was available on the real orientations of fractures (high quality scan of the slope was not available - which indeed is not the scope of the research), and information has been obtained by different techniques. Control points (Figure 3) were obtained using a single technique (manual compass and laser distance- meter / rigid tape) while planes were obtained by means of two techniques, none of them precision topographic techniques (Figure 4). Comparison with a "real" value, obtained with high precision techniques was not considered necessary, as it was not the object of the present work. The aim was to obtain relevant structural data from a slope, in a fast and simple way, and to validate as methodology for remote places. Instead of analysing the error embedded in the utilisation of fast techniques, the work has focused on the differences or similarities in data obtained (dip and dip direction) of both techniques. The distance between poles in the control planes, measured with different techniques, was considered the "quality control" - and these have been very similar ( Figure 5). The difference between the two measurements (which cannot be defined as an error, because the actual measurement is unknown) would be under $5^{\circ}$. This falls within the precision range of a hand compass $\left( \pm 2^{\circ}\right)$. This precision is totally acceptable in pre-feasibility study phases for remote locations where and many coordinates are obtained with handheld GPS

Manual data collection with a compass requires physical and safe access to the slope. However, inaccessible slopes (e.g. jungle, sea cliffs high slopes, river slopes) or those where safety is a concern frequently entail in challenging and unsafe work. In these cases, the field engineers frequently have few orientation measurements to carry out kinematic analyses, with the added inconvenience that many orientations are not representative of the sets that affect the rock mass (taken in a small, specific area). This 
fact inevitably introduces uncertainties in estimations and calculations, which prevent considerations on whether calculations are conservative, or the contrary, if unacceptable risks are being assumed.

This manuscript has highlighted the added value and representativeness of information when combining manual data obtained with a compass and data extracted from 3D point cloud - SfM. Manual data collection and visual analysis enable the a priori recognition of which planes control stability. Therefore, the combination of compass and remote data provides objectivity to the analysis. More data provide better quality to the statistical analysis, with the possibility of obtaining denser pole clouds for the planes, which would be impossible to obtain manually (Figure9).

This case study has successfully determined, with the aid of remote techniques, the orientation of the real tension crack (upper joint that limits the block) of the sliding (Figures 6, 7 and 9), which was not characterized in previously due to its inaccessibility (approximately $5 \mathrm{~m}$ high). In previous studies[28] the orientation had been inferred from discontinuity measurements of the same set, located in the accessible section of the lower part of the slope (Figure1).

The 3D point cloud has been validated by the comparison of the orientations of reference planes, measured by both techniques. The results show that orientations measured with a compass and obtained from the 3D point cloud are coherent, with orientation variation under $10^{\circ}$ for the pole vector in the most unfavourable case (i.e. $\mathrm{S}_{0}$ ), but on average $5^{\circ}$. Quality controls are always recommended when discontinuity data are collected remotely. For such, an accessible zone of the slope can be selected for gathering several control planes that belong to different joint sets. The use of a remote technique combined with classical compass and rock mass parameter descriptions is recommended.

The automatic discontinuity extraction technique via DSE software from the 3D point cloud can be considered as the most objective method, as the influence of the operator is minimal. There is also the advantage of generating a stereogram with an elevated number of poles. In this particular case it was possible to identify that discontinuities $\mathrm{S}_{0}$ and $\mathrm{J}_{2}$ were one only discontinuity set with variable orientation. However, some planes that clearly play an important role in slope stability were identified by visual inspection. An example was the $\mathrm{J}_{1}$ set, scarcely represented in semi-automatic discontinuity analysis, and its presence could even be ignored. One aspect that must be 
highlighted is that the orientation results for discontinuity sets $S_{0}$ and $J_{2}$ were similar, given that actually $\mathrm{S}_{0}$ and $\mathrm{J}_{2}$ refer to the same set. Difference in direction is due to a large undulation in the plane. This fact was not well established with manual data or with manual extraction of planes from 3D point cloud (Figure 6).

The limitations of this technique depend on the accuracy required, for example for the design of a bolting scheme in a slope reinforcement or analysis of the movements of a landslide, when additional precision steps are required. But this type of high accuracy assessments are outside the scope of this research and proposed methodology. This approach recommended for feasibility studies or early analyses - fast in situ assessments, usually carried out before any topographic measurements are available.

The remote view and global analysis of the slope provides a wider and coherent approach of the discontinuity sets of the slope. But manual data acquisition helps obtain more geomechanical parameters (e.g. roughness, infilling, weathering).

Analysis of Fisher's K distribution for each cluster indicates that, in the case of stratification $\mathrm{S}_{0}$, there are no differences between manual data collection with a compass or using SfM (Table 2). It is important to note that in joint $\mathrm{J}_{1}$ (highlighted in red, overhanging Figures 1 and 4), Fisher's K is low in the case of SfM (i.e. 32). For this set, the $\mathrm{K}$ value was 166 by manual collection with compass. This means that the orientations of this discontinuity had not been determined precisely, because data collection was limited to a restricted zone of the slope. The 3D point cloud obtained via SfM provided more data from these under-represented discontinuities. In fact, the higher number of poles corresponding to discontinuity sets $S_{0}$ and $J_{1}$ generates a higher dispersion of the respective clusters. The high value of $\mathrm{K}$ (1331) associated with set $\mathrm{J}_{2}$, obtained from the $3 \mathrm{D}$ point cloud, is not representative, as this value only means that few similar orientation planes were selected from the 3D point cloud.

Analysis carried out from orientation data obtained via semi-automatic analysis of the 3D point cloud from the entire slope has enabled the appropriate characterization of $\mathrm{J}_{1}$, whose representativeness was not significant in the lower part of the slope. In this case, Fisher's K is very low (23) because the cluster presents higher dispersion due to the elevated number of measurements obtained for this discontinuity set. The analysis has helped determine that discontinuities $\mathrm{S}_{0}$ and $\mathrm{J}_{2}$ belong to the same set. A high dispersion in the clusters of discontinuities (low $\mathrm{K}$ values) do not indicate inaccuracy but often a richest and more representative data set. 
Finally, a more rigorous kinematic analysis was carried out, in comparison with information obtained during the 2014 campaign [28]. This analysis included a higher number of poles, enabling the identification of the discontinuities responsible for the slope failure due to planar sliding (marked in Figure 9). Analysis has also enabled the identification of the precise orientation of the tension crack that delimits the key block, associated with planar failure (Figure 9). This joint set was previously measured only in less representative zones of the slope (and not at the higher part, where it is more evident) (Figure 1).

\section{Conclusions}

The study presented herein has highlighted that the combined analysis of discontinuity orientations obtained by manual procedures using a compass and from 3D point clouds enable a considerable increment in the quality of the stereograms produced, and therefore, of the orientations derived. One important advantage is that the combination of both methods improves representativeness of minority discontinuities or those with scarce dip measurements (e.g. $J_{1}$ ). These joint sets were previously underrepresented due to accessibility difficulties for manual data collection with a compass. In this sense, the analyses carried out have highlighted that the slope failure studied by Jordá et al. [28] occurred through the curve surface defined by $S_{0}$ and $J_{2}$, instead of $S_{0}$ only. The $\mathrm{J}_{1}$ set, widely represented at the upper part of the slope, is responsible for delimiting the failure in tension crack mode.

Validation of the orientations obtained from remote techniques was also carried out, comparing the values measured with a compass in three previously-defined control planes. The difference between the "control planes" measured by both techniques was reasonable, under $5^{\circ}$.

It can be concluded that digital photogrammetry, specifically the SfM technique, is a low-cost tool that is very useful, fast and easy to implement for geomechanical data collection in situ. In the case conventional methods are selected (i.e. compass) for inaccessible locations, such as high mountainous or jungle zones, these can be complemented in a relatively simple manner with the SfM technique. This research identified differences in the orientations of measured planes. The errors associated with GCP definition with compass and rigid measuring tape are acceptable for most of 
subsequent applications. Additionally, this angular deviation presents the same magnitude order than those associated with orientation measurements with a compass.

Nevertheless, it must be mentioned that remote data collection does not substitute manual data collection, but rather complements the latter, providing new data for those slope areas that were not physically accessed. Also, in situ data collection remains indispensable, as many aspects of discontinuity properties, such as fillings, alterations, etc., present an ineludibly descriptive character that requires in situ recognition.

Also, the discontinuities measured in the accessible zones can be employed, such as demonstrated herein, as control planes to compare against the orientations determined by both methods, enabling the establishment of the quality of the results provided by the remote method.

Therefore, the methodology proposed herein had its validity highlighted for the characterization and development of slope kinematic analyses with light, low-cost equipment, being an important alternative to costly and heavy terrestrial LiDAR equipment. The precision of the technique can still be improved by the use of topographical equipment that enable allocation of high-precision coordinates to the control points (GCP) employed in the restitution process.

This methodology can be easily transferred to other types of rock masses and geological settings, although it has been initially tested in slates. In fact, the technique consists in basically acquiring data with a compass wherever possible and safe, and complement the slope "scan" with a series of photographs to reconstruct the slope and extract the remaining fractures with software.

\section{Acknowledgments}

The authors wish to thank Dr. Manuel Romana for showing the studied slope for the first time in 2008, during a field trip of the "AETOS" MSc. course in tunnelling. This work was supported by the University of Alicante, within the framework of project GRE14-04. Additional funding was obtained from the Spanish Government, project number TIN2014-55413-C2-2-P.

\section{References}

[1] Jordá Bordehore L, Tomás JoverR, Arlandi Rodríguez M, Abellán Fernández A. Manual de estaciones geomecánicas. Descripción de macizos rocosos en afloramientos. 
Ed. ETSI Minas. Universidad Politécnica de Madrid. Grupo de Proyectos de Ingeniería. Madrid. 200 pp. 2016 (in spanish)

[2] Romana M, Serón JB Formatos Normalizados para la toma de datos de campo a usar en las Clasificaciones Geomecánicas RMR, Q Y SMR. Universidad Politécnica de Valencia. Jornadas Hispano-Lusas sobre Obras Subterráneas. Madrid, 15-16 septiembre 2003. http://www.stmr.es/recursos/articulos/ (in spanish)

[3] Jaboyedoff M, Oppikofer T, Abellán A, Derron M H, Loye A, Metzger R, Pedrazzini A Use of lidar in landslide in vestigations: a review. Nat Hazards. 2012;61(1):5-28. http://link.springer.com/article/10.1007/s11069-010-9634-2

[4] Abellán A, Oppikofer T, Jaboyedoff M, Rosser NJ, Lim M, Lato MJ. Terrestrial laser scanning of rock slope instabilities. Earth Surf Process Landf. 2014;39(1):80-97. http://onlinelibrary.wiley.com/doi/10.1002/esp.3493/epdf.

[5] Fonstad MA, Dietrich JT, Courville BC, Jensen JL, Carbonneau PE. Topographic structure from motion: a new development in photogrammetric measurement. Earth Surface Processes and Landforms, 2013; 38, 421-430, doi: 10.1002/esp.3366.

[6] Westoby MJ, Brasington J, Glasser NF, Hambrey MJ, Reynolds J.M. 'Structurefrom-Motion' photogrammetry: A low-cost, effective tool for geoscience applications. Geomorphology, 2012; $179, \quad 300-314, \quad$ doi: http://dx.doi.org/10.1016/j.geomorph.2012.08.021.

[7] Riquelme AJ, Tomas R, Abellan, A . Characterization of rock slopes through slope mass rating using 3D point clouds. International Journal of Rock Mechanics and Mining Sciences, 2016; 84: 165-176 http://dx.doi.org/10.1016/j.ijrmms.2015.12.008.

[8] Slob S. Automated rock mass characterisation using 3-D terrestrial laser scanning. TU $\begin{array}{llll}\text { Delft, } & \text { Delft } & \text { University } & \text { Technology. }\end{array}$ http://www.narcis.nl/publication/RecordID/oai:tudelft.nl:uuid:c1481b1d-9b33-42e4885a-53a6677843f6.

[9] Abellán A, Derron MH, Jaboyedoff M. Use of 3D Point Clouds in Geohazards, Special Issue: Current Challenges and Future Trends. Remote Sensing, 2016; 8(2), p.130. Available at: http://www.mdpi.com/2072-4292/8/2/130 [Accessed August 17, 2016]. 
[10] Riquelme AJ, Abellán A, TomásR, Jaboyedoff M A new approach for semiautomatic rock mass joints recognition from 3D point clouds, Computers \& Geosciences, 2014: 68: 38-52, http://dx.doi.org/10.1016/j.cageo.2014.03.014.

[11] Assali P, Grussenmeyer P, Villemin T, Pollet N, Viguier F. Solid images for geostructural mapping and key block modeling of rock discontinuities, Computers \& Geosciences, 2016; Volume 89, : 21-31, http://dx.doi.org/10.1016/j.cageo.2016.01.002. (http://www.sciencedirect.com/science/article/pii/S0098300416300024)

[12] Riquelme A, Abellán A, Tomás R, Jaboyedoff M, Discontinuity Set Extractor. 2014 http://rua.ua.es/dspace/handle/10045/50025.

[13] Lato MJ, Vöge M. Automated mapping of rock discontinuities in 3d lidar andphotogrammetry models. Int J Rock Mech Min Sci. 2012;54:150-158.

[14] Slob S, van Knapen B, Hack R, Turner K, Kemeny J. Method for automated discontinuity analysis of rock slopes with three-dimensional laser scanning. Transp Res Rec: J Transp Res Board. 2005;1913(1):187-194.

[15] Haneberg WC, . Directional roughness profiles from three-dimensional photogrammetric or laser scanner point clouds. In: Eberhardt E, Stead D Morrison T, eds. Rock Mechanics: Meeting Society's Challenges and Demands; 2007: 101-106 URL 〈http://www.haneberg.com/downloadables/roughness_preprint. pdf $\rangle$

[16] Riquelme AJ, Abellán A, Tomás R. Discontinuity spacing analysis in rock massesusing 3d point clouds. Eng Geol. 2015;195:185-195 http://dx.doi.org/10.1016/j. enggeo.2015.06.009,

[17] Sturzenegger M, Stead D. Close-range terrestrial digital photogrammetry and terrestrial laser scanning for discontinuity characterization on rock cuts. Eng Geol. 2009;106(3-4):163-182 http://dx.doi.org/10.1016/j.enggeo.2009.03.004,

[18] Umili G, Ferrero A, Einstein H. A new method for automatic discontinuity tracessampling on rock mass 3d model. Comput Geosci. 2013;51(0):182-192 http://dx. doi.org/10.1016/j.cageo.2012.07.026, 
[19] Olariu MI., Ferguson J F , Aiken C, Xueming Xu 2 Outcrop fracture characterization using terrestrial laser scanners: Deep-water Jackfork sandstone at Big Rock Quarry, Arkansas. Geosphere, 2008; 4(1):247-259.

[20] Sturzenegger M, Stead D, Beveridge A, Lee S, van As A . Long-range terrestrial digital photogrammetry for discontinuity characterization at Palabora open-pit mine. In Third Canada--US Rock Mechanics Symposium. 2009 pp. 1-10.

[21] Sturzenegger M, Stead D, Elmo D.. Terrestrial remote sensing-based estimation of mean trace length, trace intensity and block size/shape. Engineering Geology, 2011; 119(3), : 96-111. http://dx.doi.org/10.1016/j.enggeo.2011.02.005.

[22] JaboyedoffM., Metzger T, Oppikofer T, Couture R, Derron M H, Locat J, Turmel D, , New insight techniques to analyze rock-slope relief using DEM and 3D-imaging cloud points: COLTOP-3D software. In T. \& Francis, ed. Rock mechanics: Meeting Society's challenges and demands. Proceedings of the 1st Canada - U.S. Rock Mechanics Symposium, Vancouver, Canada, May 27-31, 2007. pp. 61-68.

[23] Gigli G, Casagli N. Semi-automatic extraction of rock mass structural data from high resolution LIDAR point clouds. International Journal of Rock Mechanics and Mining $\quad$ Sciences, 2011; 48(2): 187-198. http://dx.doi.org/10.1016/j.ijrmms.2010.11.009.

[24] Gomes RK, Oliveiraa L P L, Gonzaga Jr L, Tognolib F M, Veronezb M R, Souzab, M K, An algorithm for automatic detection and orientation estimation of planar structures in LiDAR-scanned outcrops. Computers \& Geosciences, 2016; 90:170-178.

[25] Leng X, Xiao J, Wang Y.. A multi-scale plane-detection method based on the Hough transform and region growing. The Photogrammetric Record, 2016; 31(154), pp.166192. http://doi.wiley.com/10.1111/phor.12145

[26] Li X, Chen J, Zhu H. A new method for automated discontinuity trace mapping on rock mass 3D surface model. Computers \& Geosciences, 2016; 89:118-131.

[27] Girardeau-Montant D. CloudCompare v2.6.2- 2016; www.danielgm.net/cc/

[28] Jordá-Bordehore L, Jordá-Bordehore R, Romero-Crespo P L.Kinematic Assessment of Multi-Face Round Slopes UsingHemispherical Projection Methods (HPM), Soils and Rocks, 2016; 39,2: 167-176 
[29] Lisle RJ, Leyshon PR . Stereographic Projection Techniques for Geologists and Civil Engineers. Second edition. Cambridge University Press. 2004

[30] Rocscience Inc. 2001, Dips version 5.0 Graphical and statistical analysis of orientation data. www.rocscience.comToronto, Ontario, Canada.

[31] James MR, Robson S. Mitigating systematic error in topographic models derived from UAV and ground - based image networks, Earth Surface Processes and landforms, 2014; 39-10, 1413-1420.

[32] Agisoft LLC. Image Capture Tips: Equipment and Shooting Scenarios. , 2016;. Available at: http://www.agisoft.com/pdf/tips_and_tricks/Image Capture Tips Equipment and Shooting Scenarios.pdf [Accessed June 15, 2016].

[33] Fisher R. . Dispersion on a sphere. Proc. Royal Society London 1953; , A217, :295305.

List of tables:

Table 1. Main sets of discontinuities established at the El Atazar slope in 2014 [28]

Table 2. Orientation values for the joint sets, obtained using different methods. (*) Sum of manual data and SfM data is 83 , however a similar value was measured with both techniques

List of figure captions

Figure 1. General view of the studied slope. In second plane, the El Atazar reservoir and dam (modified from [28])

Figure 2. 3D point cloud for the slope, obtained with Agisoft Photoscan Professional. Blue rectangles indicate the position and orientations of the photographs taken at the slope. 
Figure 3. GCP placed on the slope to calibrate photogrammetry images. Small circles indicate the position of control crosses on the slope, and large circles are zooms of small circles.

Figure 4. Control planes of the slope, employed to validate results, and the orientations measured with a compass.

Figure 5. Stereogram of pole orientations for control planes measured manually $(\mathrm{m})$ of from the 3D point clouds derived from Structure from Motion (sfm).

Figure 6. Pole concentration diagram obtained from: a) manual data via compass ( $n=58$ poles); b) measurements obtained via plane manual adjustment for 3D point cloud with Cloud Compare (25 poles); c) combination of data presented in a) and b); d) average orientations of the discontinuity sets derived from c). All stereograms are polar equiangular in the lower hemisphere.

Figure 7. a) Stereogram and discontinuity sets obtained semi-automatically from 3D point cloud with DSE software ( $n=370,900$ poles); b) Density estimation via kernels, isolines each $1.25 \%$. c) 3D point cloud view of the slope. d) Classified point cloud, one color per discontinuity set using DSE software.

Figure 8. Stereogram obtained with the plane automatic extractor, reduced randomly to only 300 planes (poles).

Figure 9. Stereogram for the kinematic analysis of the slope, using a combination of manual and SfM data manually extracted from the 3D point cloud. The poles of the discontinuities located within the unstable region - restricted daylight envelope are depicted in red; poles that result stable are depicted in green. The values rs, cs and ls are the limits and central dip direction of the curved slope [28] 


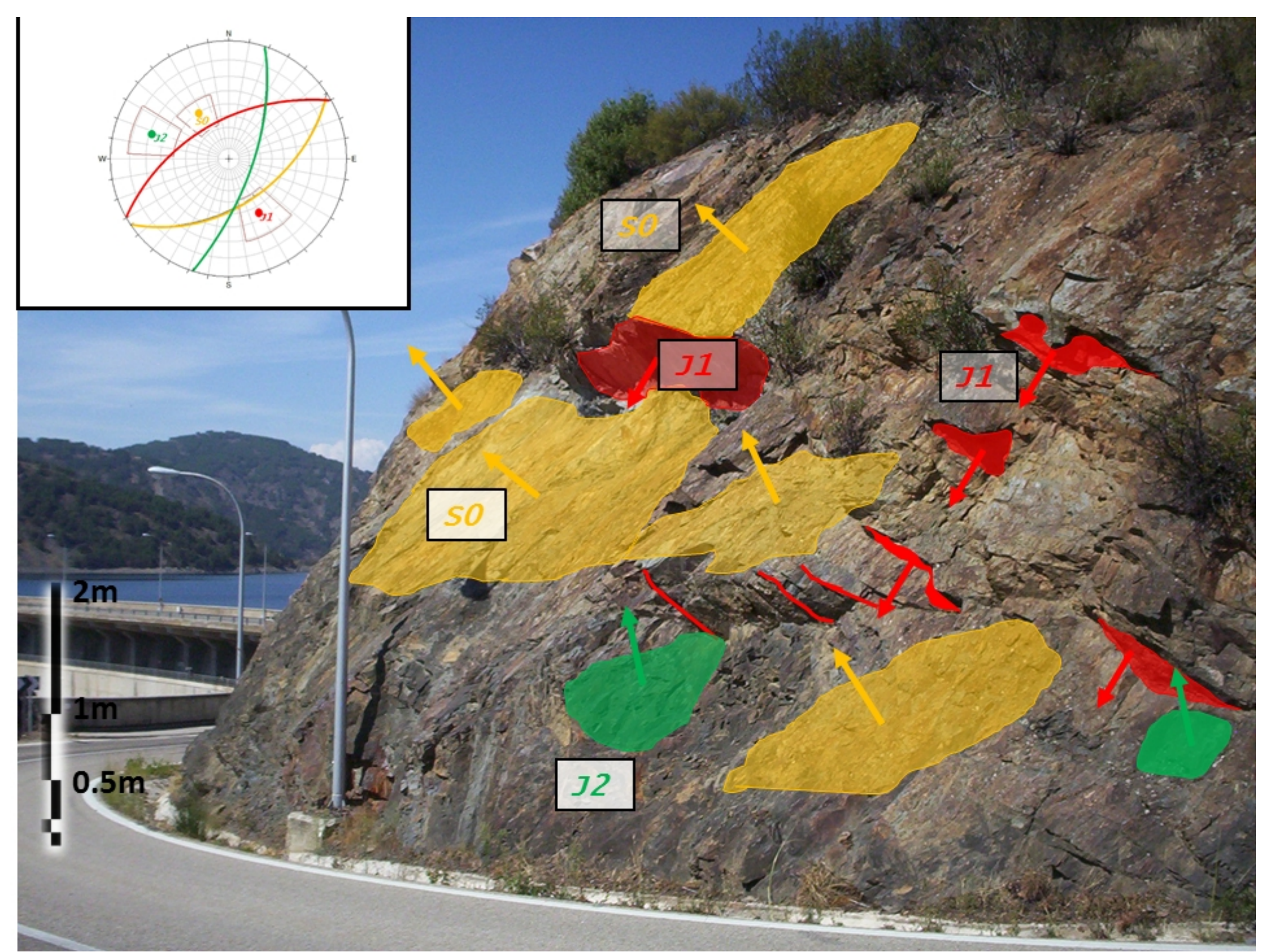




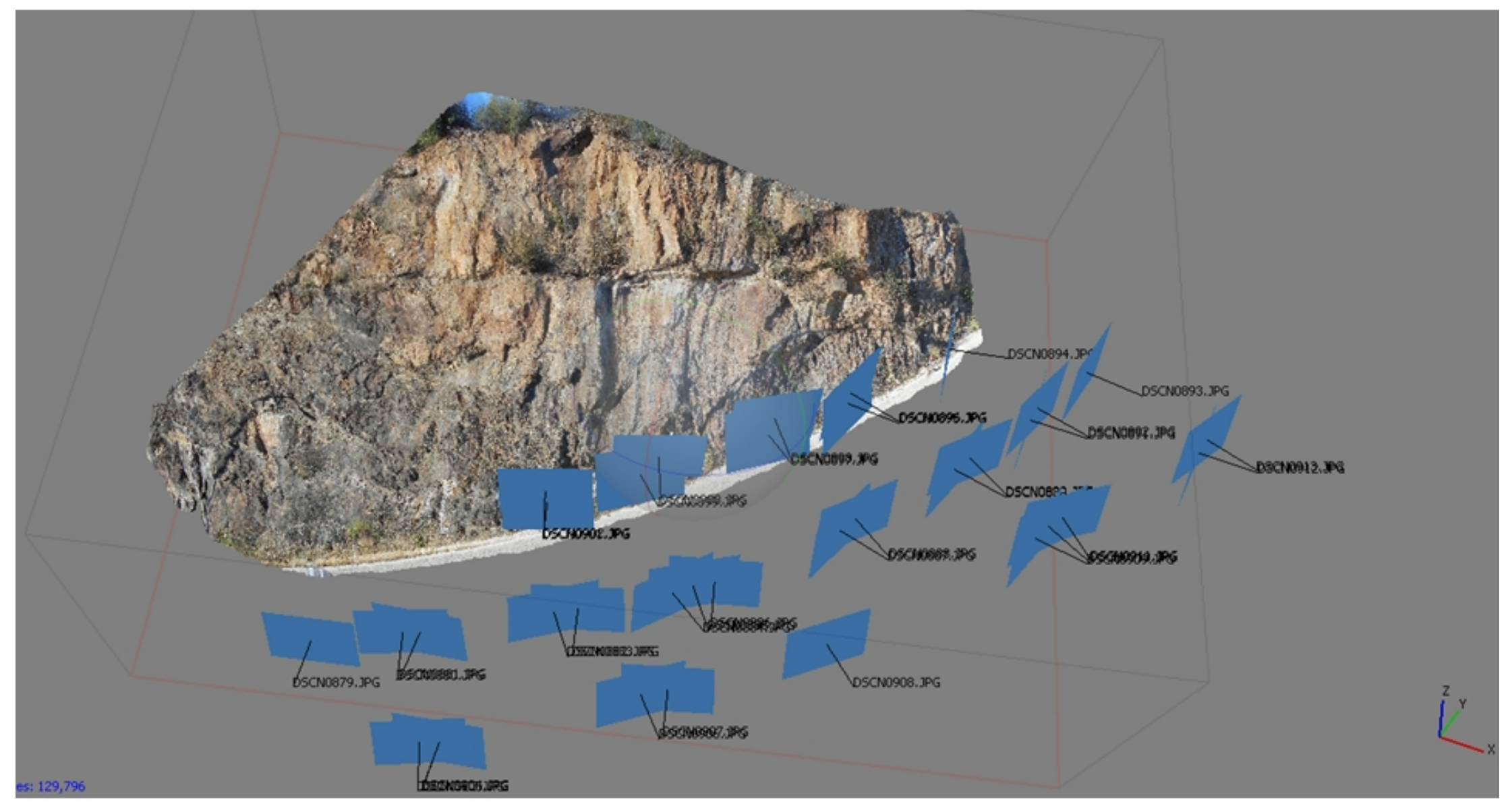




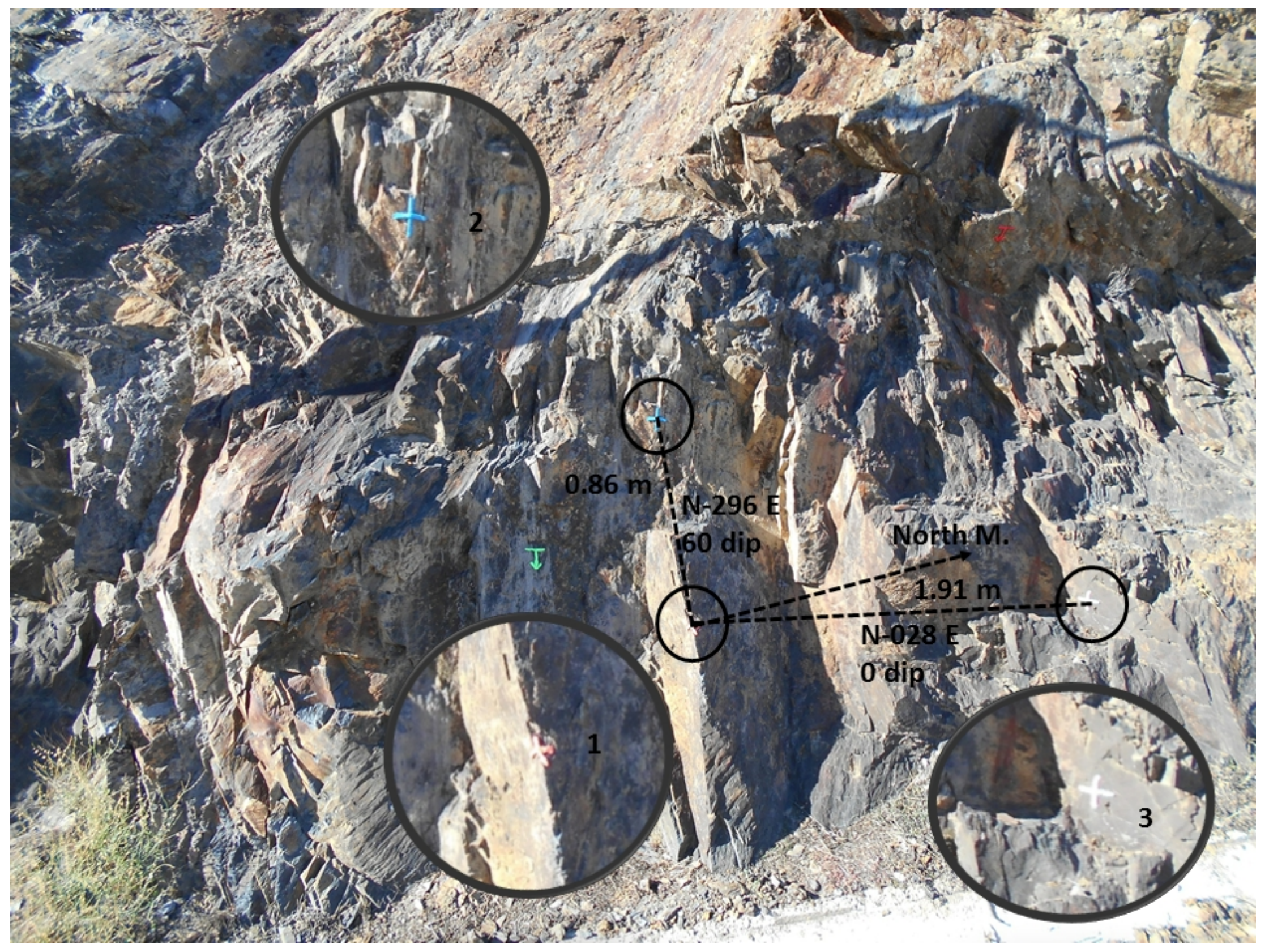




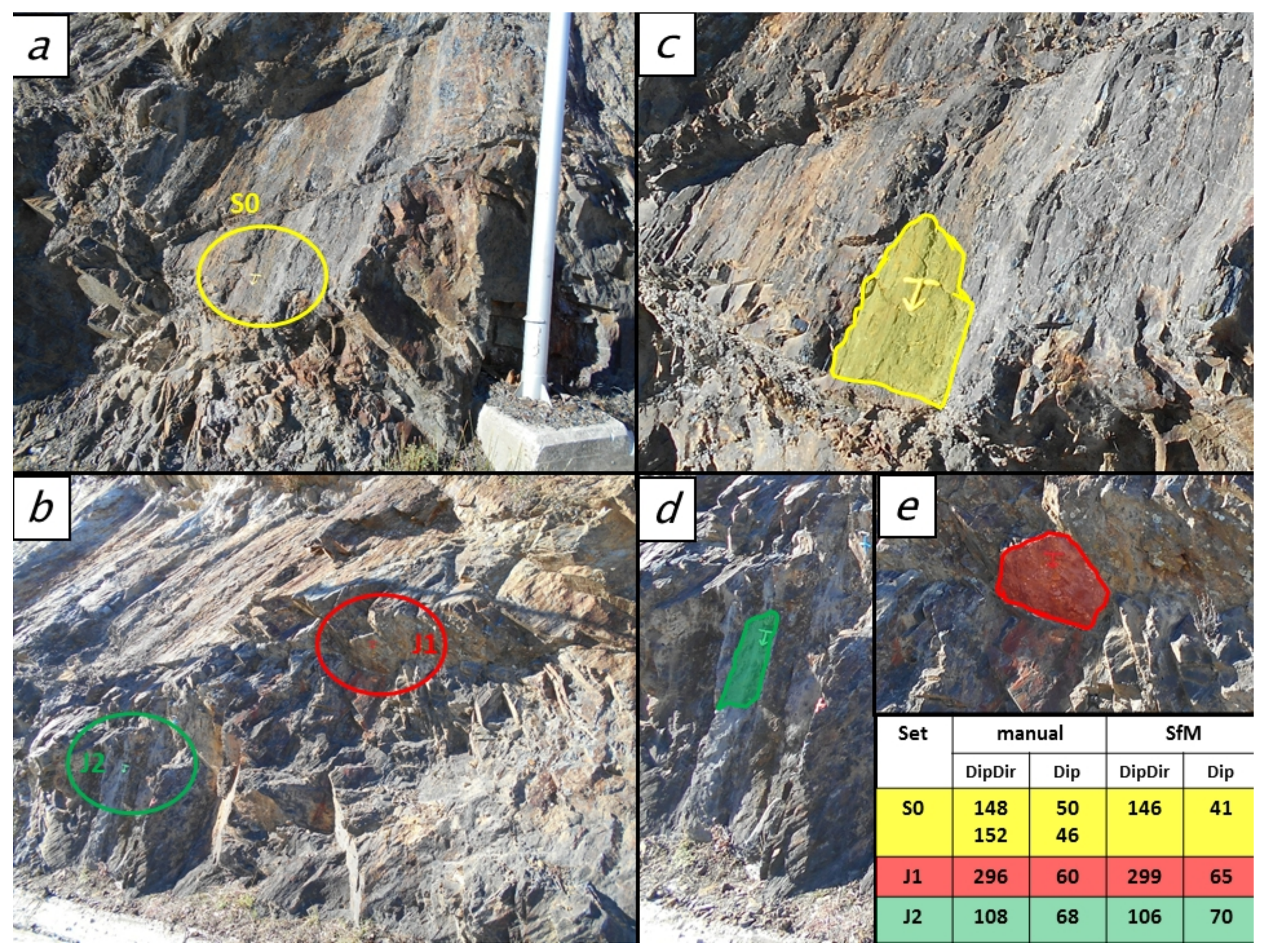




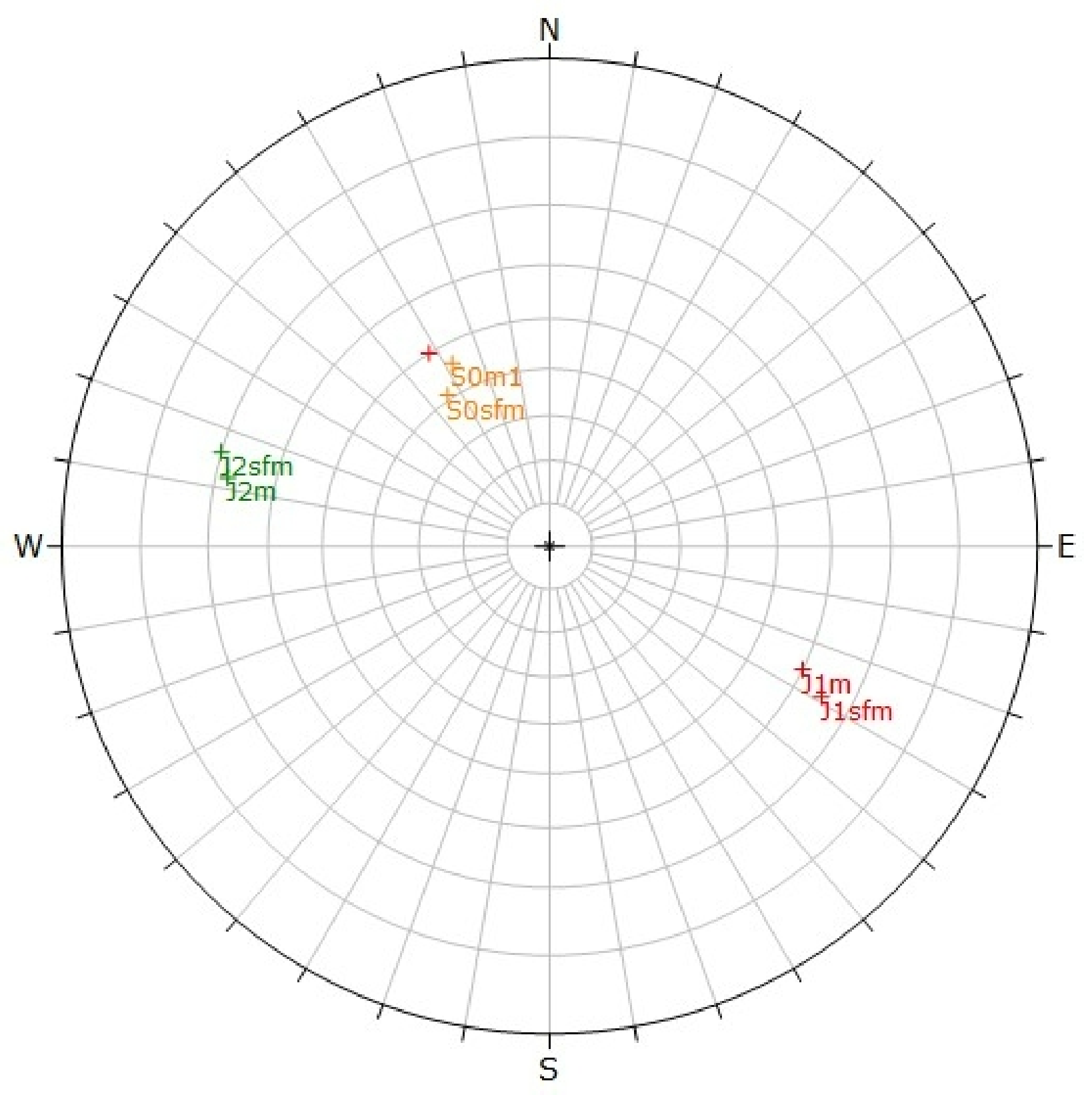



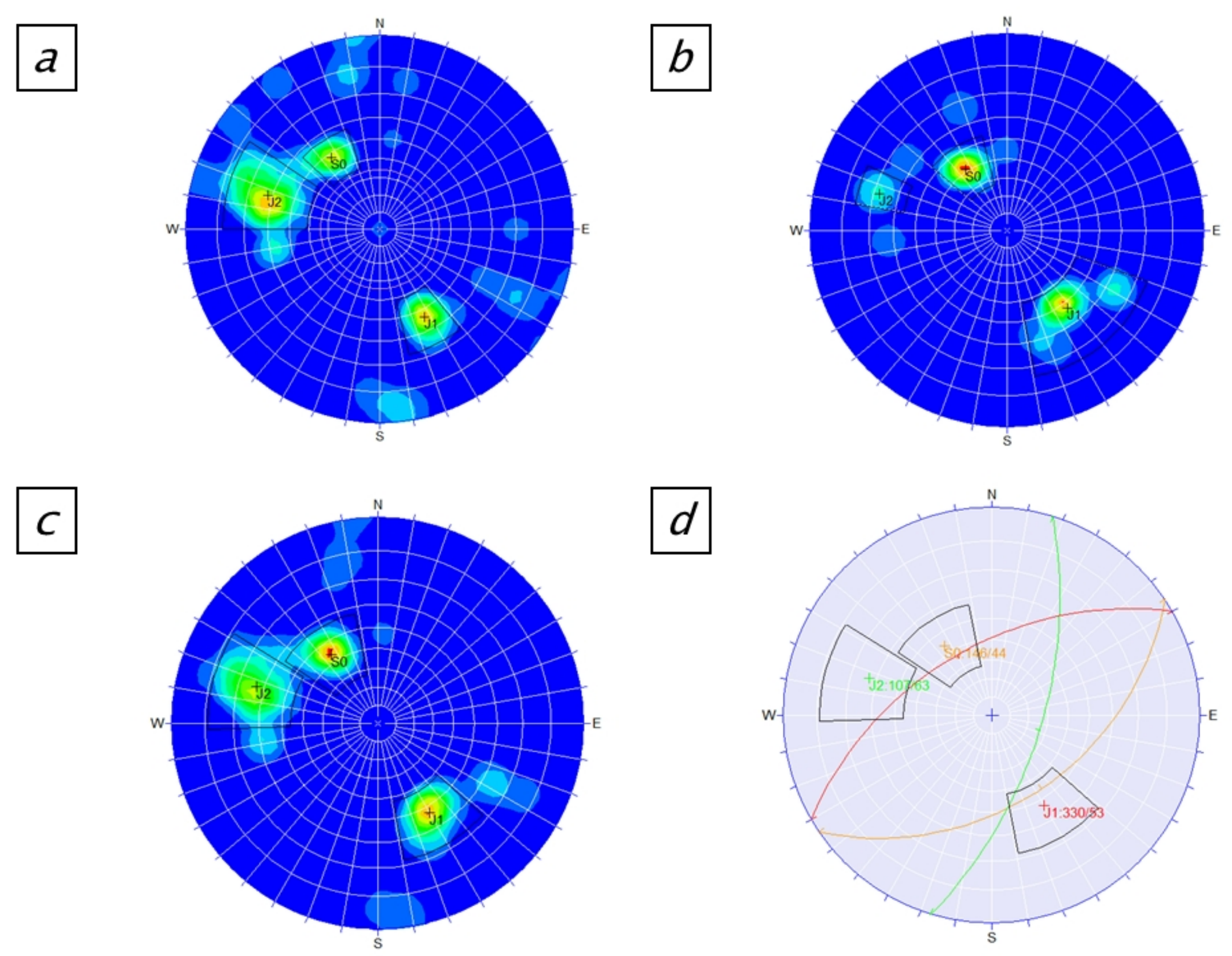

d

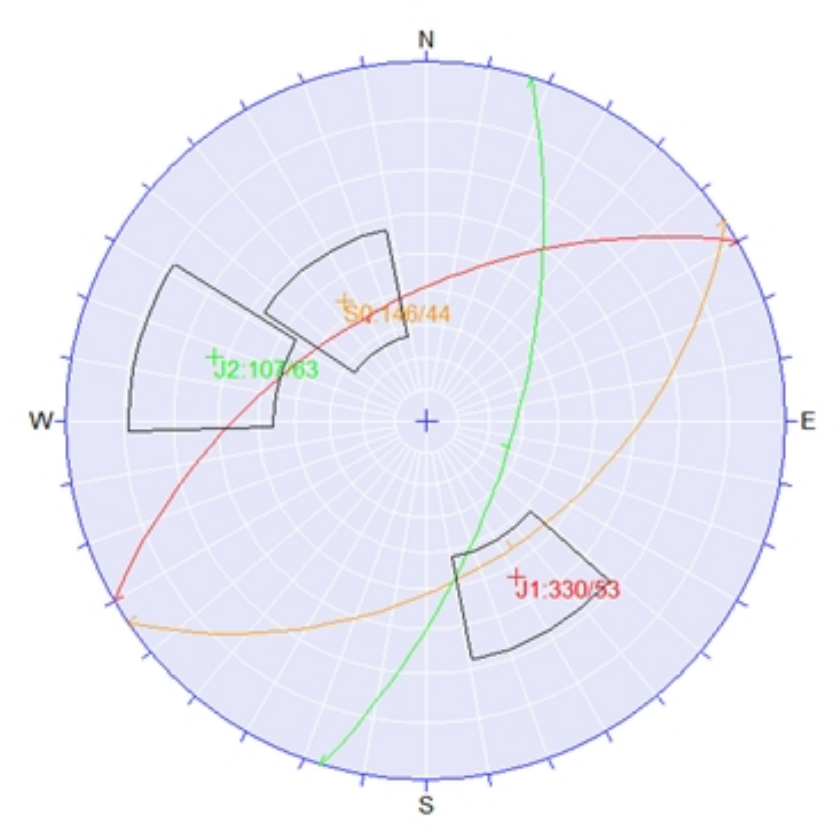




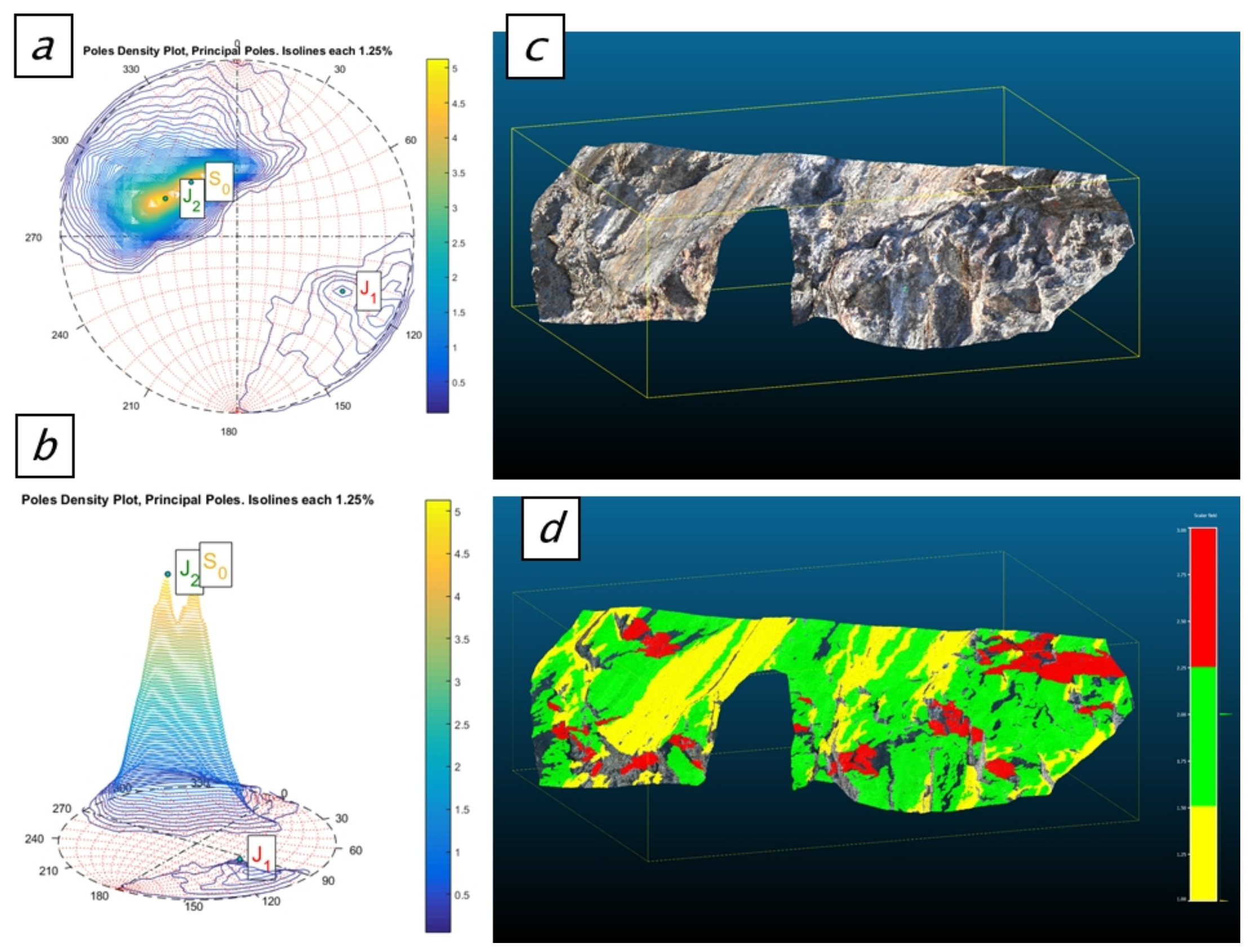




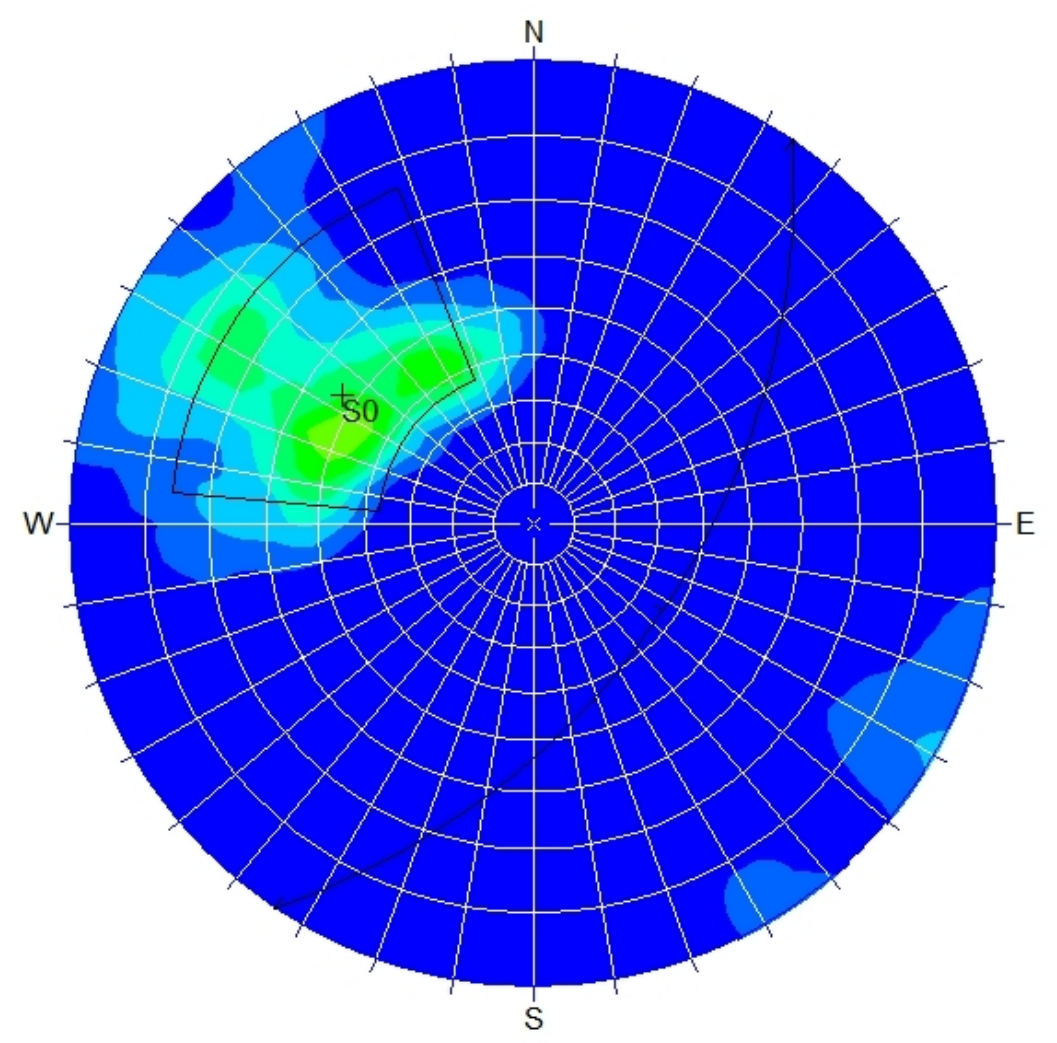

Fisher

Concentrations

$\%$ of total per $1.0 \%$ area

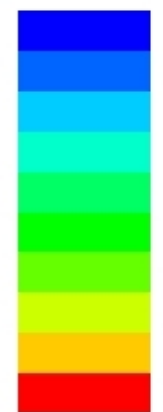

$0.00 \sim 1.50 \%$

$1.50 \sim 3.00 \%$

$3.00 \sim 4.50 \%$

$4.50 \sim 6.00 \%$

$6.00 \sim 7.50 \%$

$7.50 \sim 9.00 \%$

$9.00 \sim 10.50 \%$

$10.50 \sim 12.00 \%$

$12.00 \sim 13.50 \%$

$13.50 \sim 15.00 \%$

No Bias Correction

Max. Conc $=10.1842 \%$

Equal Angle

Lower Hemisphere

300 Poles

300 Entries 


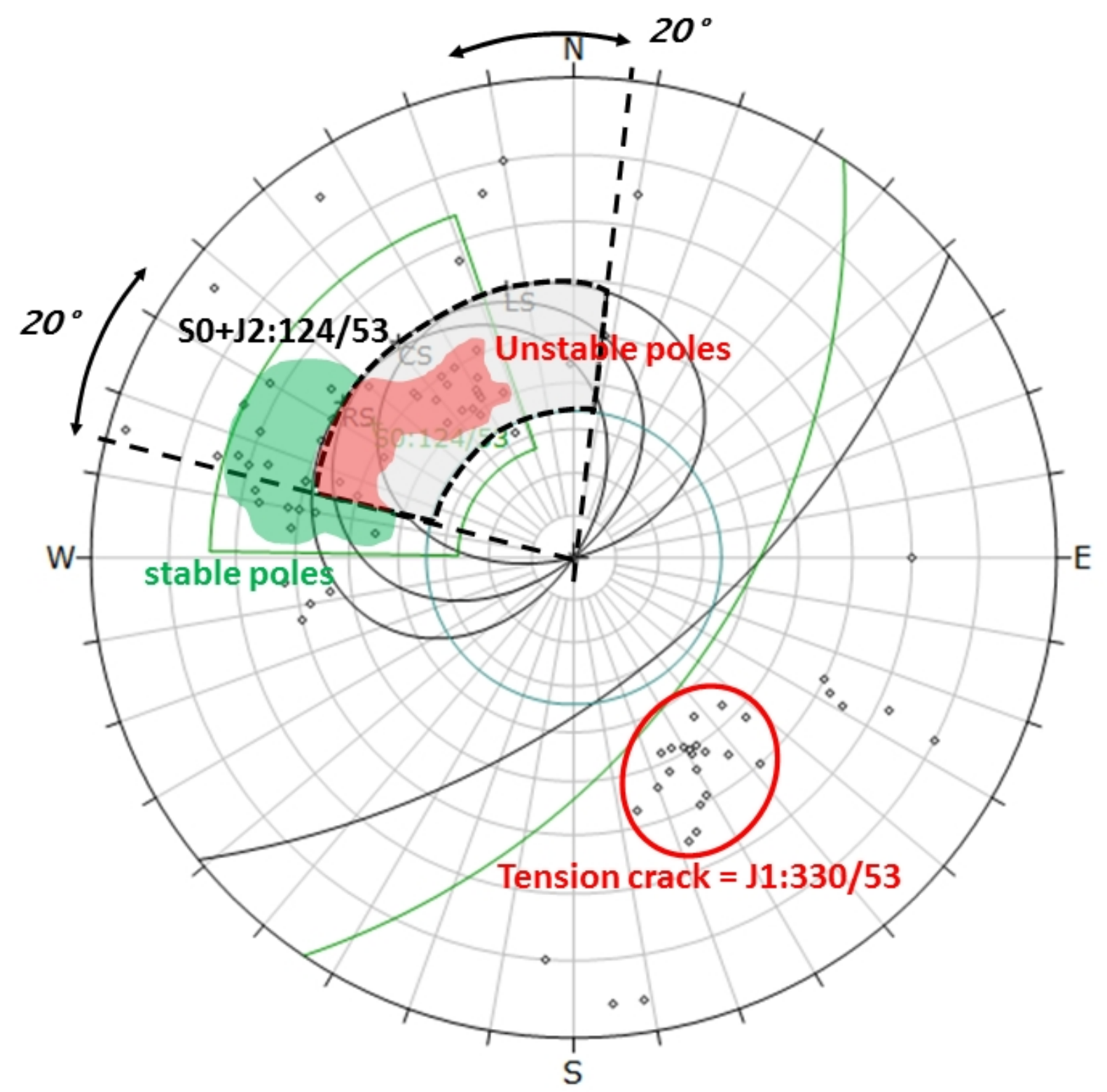




\begin{tabular}{|l|l|l|l|}
\hline Joint set & Dip angle $\left(^{\mathbf{}}\right)$ & Dip Direction $\left({ }^{\circ}\right)$ & K Fisher distribution \\
\hline J1 & 55 & 330 & 103 \\
\hline S0 (Slate -Foliation) & 48 & 146 & 114 \\
\hline J2 & 67 & 108 & 74 \\
\hline
\end{tabular}




\begin{tabular}{|c|c|c|c|c|c|c|c|c|c|}
\hline \multirow[t]{2}{*}{ Set } & \multicolumn{2}{|c|}{$\begin{array}{c}\text { Manual data } \\
\text { collection (compass) }\end{array}$} & \multicolumn{2}{|c|}{$\begin{array}{c}\text { Manual data } \\
\text { collection from } 3 D \\
\text { point cloud }\end{array}$} & \multicolumn{2}{|c|}{$\begin{array}{l}\text { Combination } \\
\text { of data } \\
\text { measured with } \\
\text { compass and } \\
\text { obtained via } \\
\text { 3D point cloud }\end{array}$} & \multirow{2}{*}{$\begin{array}{l}\text { Data collection } \\
\text { via DSE } \\
\\
\text { DipDir / Dip }\left(^{\circ}\right) \\
\text { (No K Fisher } \\
\text { determination } \\
\end{array}$} & \multicolumn{2}{|c|}{$\begin{array}{l}\text { Data collection } \\
\text { from DSE, } \\
\text { reduced to } 300 \\
\text { poles for Dips } \\
\text { software } \\
\text { comparing }\end{array}$} \\
\hline & $\begin{array}{c}\text { DipDir / Dip } \\
\left(^{\circ}\right)\end{array}$ & $\begin{array}{c}\mathrm{K} \\
\text { Fishe } \\
\mathrm{r}\end{array}$ & $\begin{array}{c}\text { DipDir / } \\
\operatorname{Dip}\left({ }^{\circ}\right)\end{array}$ & $\begin{array}{c}\mathrm{K} \\
\text { Fisher }\end{array}$ & $\begin{array}{l}\text { DipDir } \\
\text { / Dip } \\
\left(^{\circ}\right)\end{array}$ & $\begin{array}{l}\mathrm{K} \\
\text { Fisher }\end{array}$ & & $\begin{array}{l}\text { DipDir } \\
/ \text { Dip } \\
\left({ }^{\circ}\right)\end{array}$ & $\begin{array}{l}\mathrm{K} \\
\text { Fisher }\end{array}$ \\
\hline S0 & $146 / 48$ & 182 & $146 / 41$ & 166 & $146 / 44$ & 135 & $140 / 44$ & $124 / 53$ & 23 \\
\hline $\mathrm{J} 1$ & $333 / 54$ & 166 & $322 / 53$ & 32 & $330 / 53$ & 85 & $297.5 / 68$ & \multicolumn{2}{|c|}{ Undefined } \\
\hline $\mathrm{J} 2$ & $107 / 61$ & 54 & $106 / 68$ & 1331 & $107 / 63$ & 66 & $118 / 49$ & \multicolumn{2}{|c|}{ Undefined } \\
\hline $\mathrm{N}^{o}$ data & \multicolumn{2}{|l|}{58} & \multicolumn{2}{|c|}{25} & \multicolumn{2}{|c|}{$83^{*}$} & 370900 & \multicolumn{2}{|c|}{$\begin{array}{l}300 \text { (reduced } \\
\text { from } 370900)\end{array}$} \\
\hline
\end{tabular}

